\section{Effect of bile acids on fibroblast proliferation and viability}

\author{
Abstract \\ Purpose To examine the in vitro effects of bile \\ acids and salts on the viability, growth and \\ morphology of human Tenon's capsule \\ fibroblasts.
}

Methods Human Tenon's capsule fibroblasts were grown from explants in culture and used between passages 3 and 5 . Fibroblasts $(n=3)$ were treated in triplicate with deoxycholic acid (DA), sodium deoxycholate $(\mathrm{NaD})$ and cholic acid (CA) at concentrations between $50 \mu \mathrm{M}$ and $1 \mathrm{mM}$. Cell viability and growth were assessed with trypan blue staining and haemocytometer counting, and a colorimetric (MTT) assay. Morphology was assessed with light microscopy and cresyl violet staining. Results A dose-dependent decrease in viability was observed following bile acid treatment ( 24 and $48 \mathrm{~h}$ ) where the effects of DA $>\mathrm{NaD}>\mathrm{CA}$. The $\mathrm{LD}_{50}$ values at $48 \mathrm{~h}$ for $\mathrm{DA}$, $\mathrm{NaD}$ and CA were $300 \mu \mathrm{M}, 400 \mu \mathrm{M}$ and $720 \mu \mathrm{M}$ respectively. Cell growth following bile acid treatment was reduced compared with controls. Fibroblasts treated with bile acids displayed a loss of nomal spindleshaped morphology and multiple processes, some with varicosities, extended from many cells. These changes were dose-dependent, and at higher concentrations cells became detached and were non-viable (trypan-bluepositive). Extensive cell death was observed in cultures treated with DA $400 \mu \mathrm{M}, \mathrm{NaD} 500 \mu \mathrm{M}$ and CA $800 \mu \mathrm{M}$.

Conclusions Lower doses of bile acids and salts reduced in vitro fibroblast growth associated with morphological changes; higher doses induced fibroblast cytotoxicity. These observations suggest that bile acids and salts, in particular DA, may be useful in regulating wound fibrosis following trabeculectomy surgery.

Key words Bile acids and salts, Human Tenon's capsule, Fibroblasts, Glaucoma,

Trabeculectomy, Wound healing

Glaucoma filtration surgery or trabeculectomy reduces intraocular pressure (IOP) by forming a new drainage channel for aqueous humour outflow. ${ }^{1,2}$ The successful lowering of IOP
K. RAMAESH, F.A. BILLSON,

M.C. MADIGAN following trabeculectomy depends on the healing response after surgery; trabeculectomy failure is most likely to occur when subconjunctival scarring, secondary to fibroblast proliferation, occludes the trabeculectomy and encystation of the filtering bleb occurs. ${ }^{1,2}$ The failure rate is significantly higher in the paediatric age group where the wound healing response is more vigorous. ${ }^{1,3,4}$ Agents that can inhibit fibroblast proliferation and scar formation, including 5-fluorouracil (5-FU) and mitomycin C, are commonly used to reduce the incidence of trabeculectomy failure. ${ }^{2}$ However, these agents may require frequent injections and have been associated with ocular side-effects including epithelial toxicity, wound leaks, and an increased risk of endophthalmitis. ${ }^{1,2}$

Clinical observations and in vitro studies indicate that bile acids and salts may regulate wound healing and can inhibit human fibroblast proliferation. ${ }^{5,6}$ Recent studies have also shown that bile acids and salts can inhibit proliferation and induce differentiation of HL-60 promyelocytic leukaemia cells, ${ }^{7}$ and may induce apoptosis of colonic goblet cells ${ }^{8}$ and Epstein-Barr virus (EBV)-transformed lymphocytes. ${ }^{9}$ Bile salts have been trialled on rabbit corneas as possible penetrationenhancing agents for various drugs, without apparent ocular irritation or increases in corneal hydration. ${ }^{10}$ Systemically administered bile acids (ursodeoxycholic and chenodeoxycholic acid) have also been used over prolonged periods, with minimal side-effects, for patients with primary biliary cirrhosis and choleostasis, ${ }^{11,12}$ further suggesting these compounds have low toxicity.

To further assess the potential of bile acids and salts to inhibit fibroblast growth, we investigated the effects of three bile acids and salts (deoxycholic acid, sodium deoxycholate and cholic acid) on the viability, growth and morphology of cultured human Tenon's capsule fibroblasts.

\author{
K. Ramaesh \\ F.A. Billson \\ M.C. Madigan \\ Department of Clinical \\ Ophthalmology \\ Save Sight Institute \\ University of Sydney \\ NSW 2006 \\ Australia
}

M.C. Madigan

Department of Clinical

Ophthalmology

Sydney Hospital

GPO BOX 4337

Sydney

NSW 2001

Australia

Tel: +61 293827315

Fax: +61 293827318

e-mail:

michele@eye.usyd.edu.au

Supported by the Sydney Foundation for Medical Research (MCM), the Ophthalmic Research Institute of Australia and the Sydney Eye Hospital Foundation 


\section{Materials and methods}

\section{Fibroblast cultures}

Pieces of Tenon's capsule were obtained with consent at the time of cataract surgery, from 4 patients aged 17, 39, 65 and 70 years. The tissue was transported in Hank's buffered saline solution (HBSS; Trace Biosciences). The biopsy specimens were minced into small pieces and explants incubated at $37^{\circ} \mathrm{C}$ in Dulbecco's minimum essential medium (DMEM) containing 10\% fetal bovine serum, $50 \mathrm{mg} / \mathrm{ml}$ penicillin and streptomycin and $2 \mathrm{mM}$ L-glutamine (Trace Biosciences). Explants were cultured for 3 weeks and the medium changed twice weekly until fibroblasts reached confluence. Following removal of the explants, adherent fibroblasts were rinsed twice in HBSS and trypsinised with $0.05 \%$ trypsin $/ 0.02 \%$ EDTA in HBSS (Trace Biosciences) and passaged into $25 \mathrm{~cm}^{2}$ flasks. When confluent, fibroblasts were again trypsinised and then passaged into $75 \mathrm{~cm}^{2}$ flasks. Fibroblasts between passage 3 and 5 were used for all experiments.

\section{Immunocytochemistry}

A mouse anti-human fibroblast antibody (Dako Aust.) that stains for prolyl 4-hydroxylase, an enzyme found in fibroblasts, was used to assess the homogeneity of the fibroblast cultures. Fibroblasts grown on coverslips for $48 \mathrm{~h}$ were immunostained as follows. Coverslips were rinsed in Dulbecco's phosphate-buffered saline (DPBS; $\mathrm{pH}$ 7.2), fixed in acetone at $-20^{\circ} \mathrm{C}$, rinsed again, then incubated in primary antibody (diluted 1:50). After further rinsing, cells were incubated in a biotinylated secondary antibody (diluted 1:50) (Amersham Aust.), and bound antibody detected with an avidin-biotin peroxidase labelling technique (Vectastain, Vector Labs, USA) using 3,3'-diaminobenzidine tetrahydrochloride.

\section{Bile acids}

Stock solutions of deoxycholic acid (DA), sodium deoxycholate $(\mathrm{NaD})$ and cholic acid (CA) (Sigma Aust.) were prepared as follows. CA $(20 \mathrm{mM})$ and DA $(50 \mathrm{mM})$ were dissolved in absolute ethanol; $\mathrm{NaD}$ was prepared as a $50 \mathrm{mM}$ stock solution in HBSS. The CA and DA stock solutions were stored at $4{ }^{\circ} \mathrm{C}$ and discarded after 2 weeks; fresh stock solutions of $\mathrm{NaD}$ were made for each experiment. To examine for $\mathrm{pH}$ effects of bile acids and salts prior to viability experiments, the $\mathrm{pH}$ of the culture medium plus a range of concentrations of bile salts and acids (from $50 \mu \mathrm{M}$ to $1 \mathrm{mM}$ ) was assessed and found to remain between $\mathrm{pH} 7.2$ and 7.4. Previous in vitro studies indicate that doses of bile acids from $25 \mu \mathrm{M}$ to $3.1 \mathrm{mM}$ can induce growth inhibition and cytotoxicity in a variety of cell types including fibroblasts. ${ }^{6,7,9}$ A range of concentrations of bile acids from $50 \mu \mathrm{M}$ to $1 \mathrm{mM}$ was therefore used in the present study.

\section{Effect on fibroblast viability}

To assess the effect of varying concentrations of bile acids on cell viability, fibroblasts from three explants $(17,65$ and 70 years) were seeded in triplicate into 24-well plates at a concentration of $10^{4}$ cells per well. After $24 \mathrm{~h}$ the medium was replaced and bile acids added to give final concentrations of 50,100,200,300,400,500 $\mu \mathrm{M}$ for DA and $\mathrm{NaD}$. For $\mathrm{CA}$, treatments of $600 \mu \mathrm{M}, 800 \mu \mathrm{M}$ and $1 \mathrm{mM}$ were also studied. For $\mathrm{NaD}$, parallel untreated controls were examined. For DA and CA, where ethanol was used as the diluent, triplicate wells were treated with a volume of ethanol equal to that used for the highest concentration of DA or CA. For example, $20 \mu$ of $50 \mathrm{mM}$ stock DA was added to cells in $2 \mathrm{ml}$ medium to give a final concentration of $500 \mu \mathrm{M}$ DA; controls were treated with $20 \mu \mathrm{l}$ ethanol. After $24 \mathrm{~h}$ fibroblasts were examined and photographed, then trypsinised as above. Cell viability was assessed with trypan blue staining and haemocytometer counting.

In separate experiments, fibroblasts were grown on coverslips, treated with various doses of bile acids as described above, fixed in $2 \%$ paraformaldehyde/DPBS ( $\mathrm{pH}$ 7.2), and stained with cresyl violet. The coverslips were mounted on slides in glycerol and photographed.

\section{Effect on fibroblast growth}

To test the effects of $\mathrm{DA}, \mathrm{NaD}$ and $\mathrm{CA}$ on cell growth, fibroblasts from three explants $(39,65$ and 70 years) were seeded in triplicate at $2 \times 10^{4}$ cells per well into 24 -well plates. After $24 \mathrm{~h}$, the medium was replaced and cells treated with $\mathrm{DA}$ and $\mathrm{NaD}$ to give final concentrations of $200 \mu \mathrm{M}, 300 \mu \mathrm{M}$ and $400 \mu \mathrm{M}$. For CA, concentrations of $200 \mu \mathrm{M}, 400 \mu \mathrm{M}$ and $600 \mu \mathrm{M}$ were also tested. At 24 and $48 \mathrm{~h}$, cultures were examined and photographed. The total number of viable cells was then counted using trypan blue staining and a haemocytometer. Parallel untreated and alcohol-treated (for DA and CA) controls as described above were also examined. Cell counts from the three specimens, assessed in triplicate wells, were averaged. Differences in cell counts between bile-acidtreated specimens and control specimens (untreated controls and ethanol-treated controls) were assessed for each bile acid and the appropriate control at 24 and $48 \mathrm{~h}$ using a paired $t$-test, where $p<0.05$ was considered significant.

The effects of $\mathrm{DA}, \mathrm{NaD}$ and $\mathrm{CA}$ on fibroblast growth were also assessed using a colorimetric assay (MTT Kit 1; Boehringer Mannheim Aust.). Fibroblasts from three explants $(39,65$ and 70 years) were seeded in triplicate at $5 \times 10^{3}$ cells per well in 96-well plates, and treated for 24 and $48 \mathrm{~h}$ with bile acids and salts as described above. Tetrazolium dye (3-[4,5-dimethylthiazol]-2-yl-2,5diphenyl tetrazolium bromide or MTT) was added, and cells incubated for $4 \mathrm{~h}$ at $37^{\circ} \mathrm{C}$ (MTT is converted by viable cells to an insoluble, purple formazan salt). Formazan salts were solubilised overnight at $37^{\circ} \mathrm{C}$ and the absorbance quantified with an ELISA plate reader (Bio-Rad; $570 \mathrm{~nm}$ with $655 \mathrm{~nm}$ reference). 


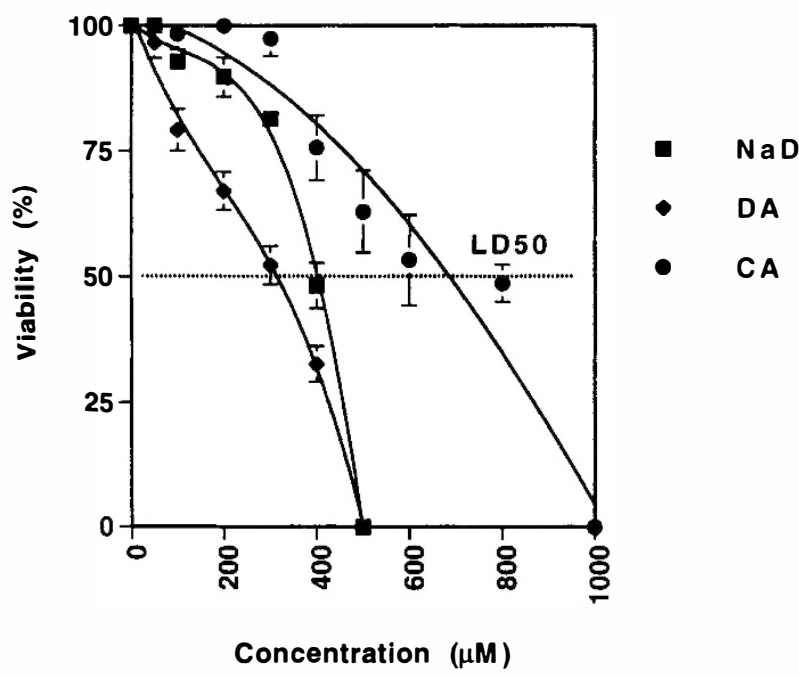

Fig. 1. Viability of fibroblasts treated for $24 \mathrm{~h}$ with a range of concentrations of deoxycholic acid (DA), sodium deoxycholate (NaD) or cholic acid (CA), where the $L D_{50}$ is approximately $300 \mu \mathrm{MDA}$, $400 \mu \mathrm{M} \mathrm{NaD}$ and $720 \mu \mathrm{MCA}$, respectively. Error bars show the standard deviation $(S D)$.
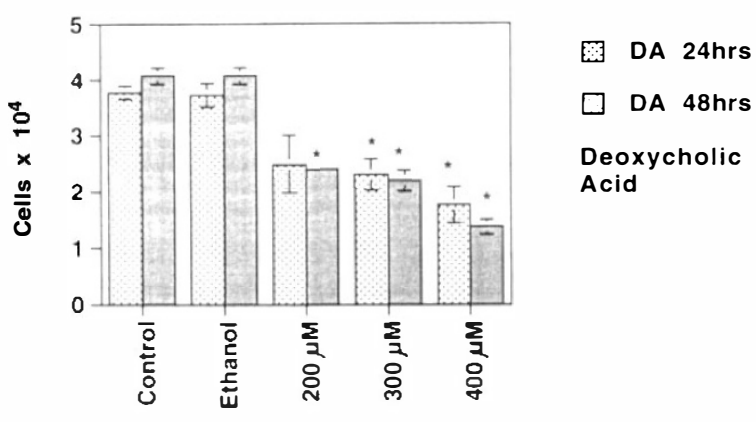

DA $48 \mathrm{hrs}$

Deoxycholic Acid

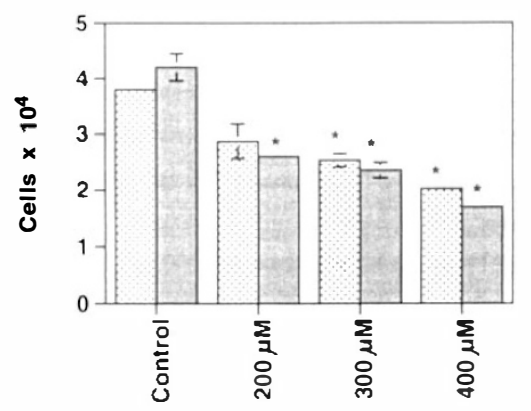

NaD 24hrs

$\square \mathrm{NaD} 48 \mathrm{hrs}$

Sodium Deoxycholate

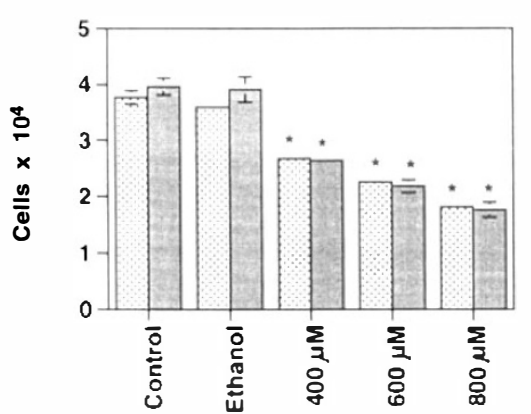

Fig. 2. Cell counts for a range of concentrations of $D A, N a D$ and $C A$, after $24 h$ and $48 \mathrm{~h}$ of treatment. The decrease in cell number following treatment with bile acids and salts is time-and dose-dependent, where the effect of $D A>N a D>C A$. Error bars show the $S D ;{ }^{*} \mathrm{p}<0.05$, paired t-test.

\section{Results}

Dose response

In untreated control and alcohol-treated control cultures, cell viability was greater than $95 \%$ for all experiments. Following treatment with bile acids and salts for $24 \mathrm{~h}$, viability decreased in a dose-dependent fashion with an $\mathrm{LD}_{50}$ of approximately $300 \mu \mathrm{M}$ DA, $400 \mu \mathrm{M} \mathrm{NaD}$ and $720 \mu \mathrm{M}$ CA respectively (Fig. 1).

\section{Cell growth}

In untreated and alcohol-treated controls, cell numbers increased from approximately $3.8 \times 10^{4}$ cells at $24 \mathrm{~h}$ to approximately $4.1 \times 10^{4}$ cells at $48 \mathrm{~h}$ (Fig. 2). Cell numbers in cultures treated with a range of concentrations of DA, NaD and CA for 24 and $48 \mathrm{~h}$ were
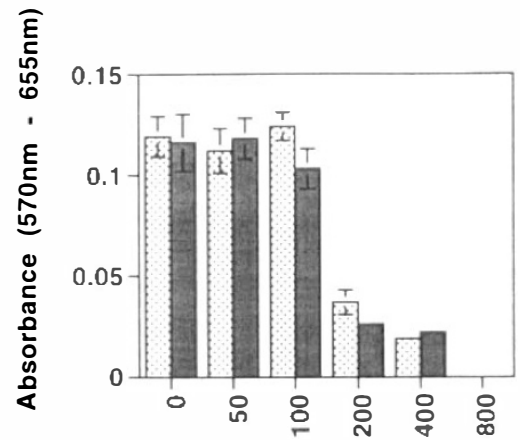

2 DA 24hrs

DA 48hrs

Deoxycholic Acid

Concentration $(\mu M)$

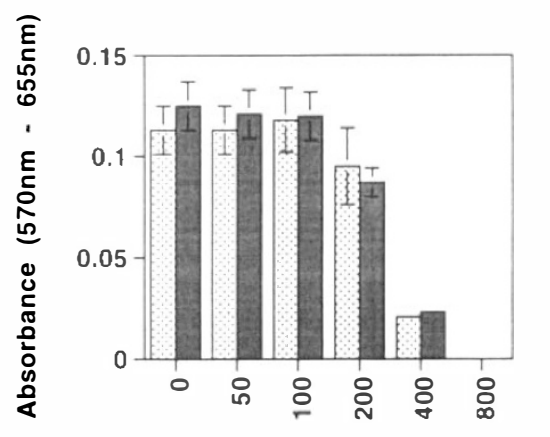

NaD 24hrs

NaD 48hrs

Sodium

Deoxycholate

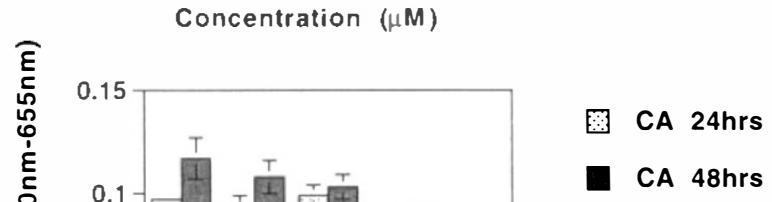

Cholic Acid
Cholic Acid

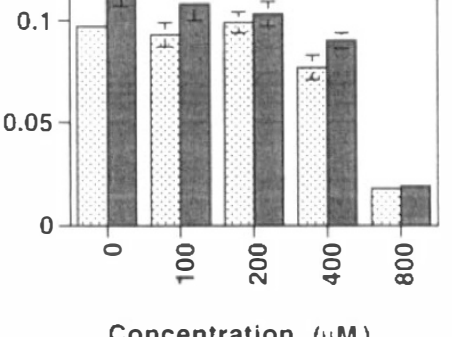

Concentration $(\mu M)$

Fig. 3. MTT assays after 24 and $48 \mathrm{~h}$ of treatment. A time- and dosedependent decrease in absorbance (viable cells) of treated cultures is seen, particularly for higher doses. In untreated and ethanol-treated (not shown) controls, an increased absorbance is seen at $48 \mathrm{~h}$ compared with $24 \mathrm{~h}$. Error bars show the SD. 

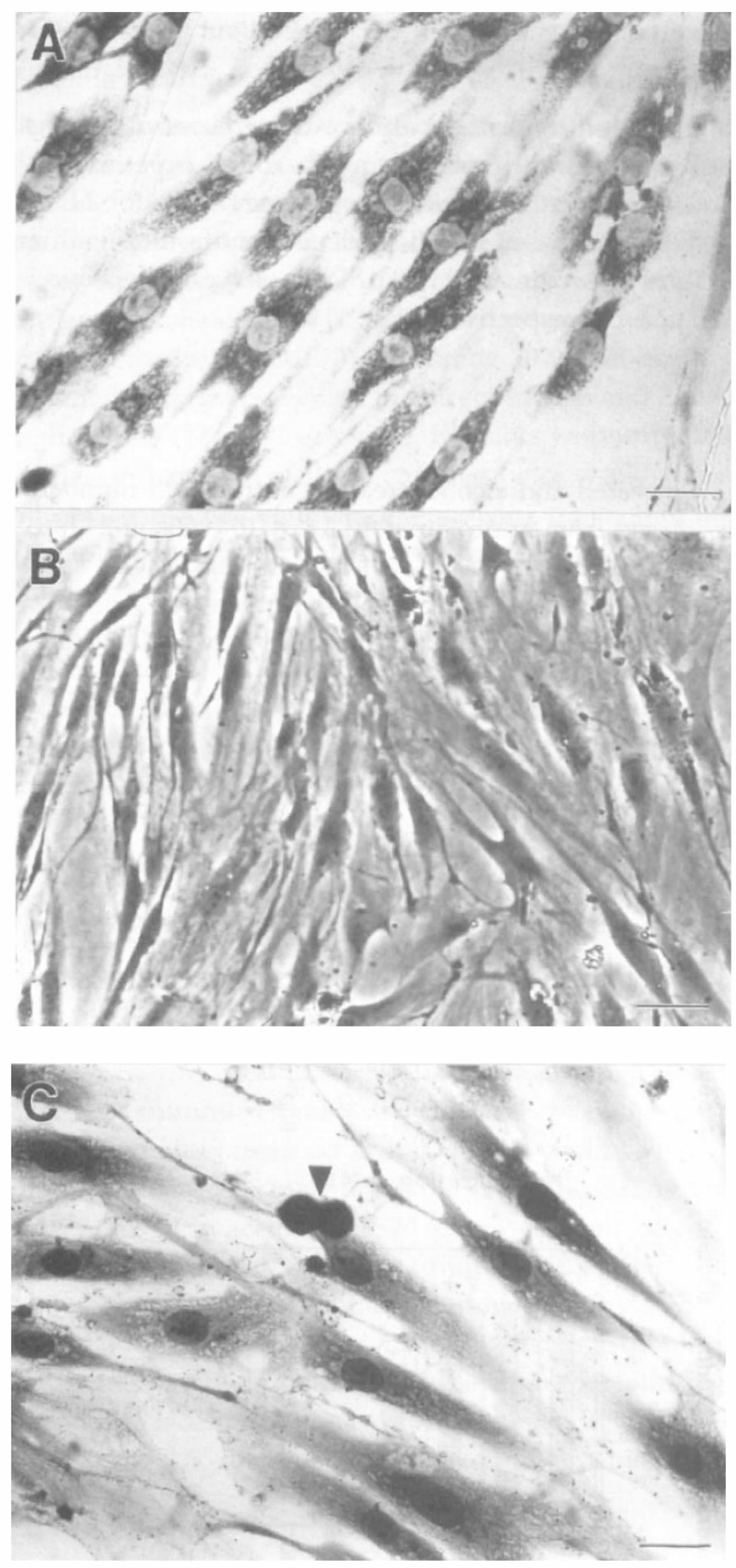

Fig. 4. Photomicrographs of control Tenon's capsule filbroblasts growen from explants. (A) Immunocytochemistry of fibroblast cultures using an anti-fibroblast antibody; cytoplasmic staining is seen in all colls indicating homogeneous fibroblast cultures. (B) With phuse-contrinst microscopy, control fibroblasts display a spindle-shaped confluent morphology. Ethanol-treated controls had a similar appearance not showen). (C) Cresyl inolet staining further illustrates the spindleshaped morphology of control fibroblasts; a mitotic cell is also itisible (arrozohead). Scale bars represent: (A), (C), $25 \mu \mathrm{M}$; (B), 130 $\mu \mathrm{M}$.

significantly decreased compared with controls $(p<0.05$, paired $t$-test) (Fig. 2). However, for similar

concentrations, DA-treated cultures had fewer cells than $\mathrm{NaD}$ - or CA-treated cultures (Fig. 2). MTT assays (where absorbance is proportional to viable cell numbers) also indicated that, for similar concentrations, DA induced greater decreases in fibroblast viability than either $\mathrm{NaD}$ or CA (Fig. 3).
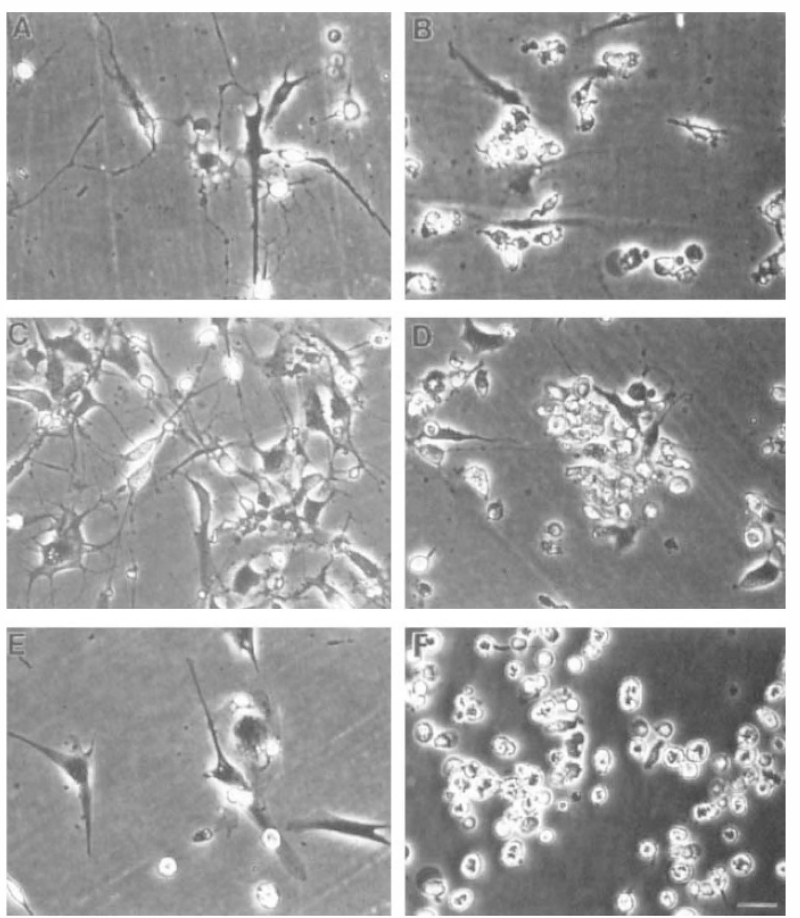

Fig. 5. Phase-contrast photomicrographs of fibroblasts after $48 \mathrm{~h}$ of treatment with bile acids and salts. Fibroblasts treated with $D A>$ 10) $\mu \mathrm{M}$ showe loss of spindle'shaped morphology, and multiple processe's, some beaded, extend from many cells $(A)$. These changes are more obvious at higher concentrations and for $D A \geqslant 300 \mu M$ numerous rounded detached (non-iviable') cells are seen (B). Similar morphological changes were obsereed in $\mathrm{NaD}$-treated $(C, D)$ and CA-treated fibroblast cultures (E, F). Extensize cell death was observed in cultures treated with DA 40)() $\mu \mathrm{M}, \mathrm{NaD} 5(0) \mu \mathrm{M}$ or $\mathrm{CA} 800 \mu \mathrm{M}$. Scale bar represents $110 \mu \mathrm{M}$.

\section{Morphology}

Immunocytochemistry of cultures from each explant, using an anti-fibroblast antibody, revealed homogeneous fibroblasts with cytoplasmic staining of all cells (Fig. 4A). Untreated or alcohol-treated fibroblasts grew as attached flat spindle-shaped cells in culture (Fig. 4B, C).

Concentrations of $100 \mu \mathrm{M}$ and $200 \mu \mathrm{M} \mathrm{NaDA}, \mathrm{DA}$ and CA did not produce marked changes in cell morphology or cell detachment. However, fibroblasts treated with $300 \mu \mathrm{M}$ and $400 \mu \mathrm{M}$ DA and $\mathrm{NaD}$ showed evidence of cell detachment, especially with DA, and dead cells were also visible; some viable cells were still attached $48 \mathrm{~h}$ after treatment (Fig. 5A-D). The attached cells displayed distinct changes, with loss of the spindleshaped morphology normally seen in control cultures, and extension of multiple long thin processes from the cell body (Fig. 5A-D). Varicosities were sometimes visible along these processes (Fig. 5A, C). Similar changes were noted for $600 \mu \mathrm{M}$ and $800 \mu \mathrm{M} \mathrm{CA}$ (Fig. 5E, F). With phase-contrast microscopy, fibroblasts incubated for $24 \mathrm{~h}$ with $\geqslant 500 \mu \mathrm{M} \mathrm{NaD}$ or $\mathrm{DA}$, and $\geqslant 1 \mathrm{mM} \mathrm{CA}$, were detached and non-viable, as indicated by trypan blue staining.

In separate experiments, fibroblasts were grown on coverslips, treated as above with bile acids and salts, and stained with cresyl violet. Control and alcohol-treated 
fibroblasts displayed normal spindle-shaped morphology; cell nuclei were clearly stained with cresyl violet and mitotic cells were sometimes visible (Fig. 4C). The loss of spindle-shaped morphology associated with higher doses of bile salts and acids was also clearly visible in cresyl-violet-stained cultures (not shown).

\section{Discussion}

The outcome of glaucoma filtration surgery has been considerably improved with the use of agents such as 5-FU (an antimetabolite) and mitomycin C (an antiproliferative), which can inhibit fibroblast proliferation and scarring of the trabeculectomy site. ${ }^{1,2}$ Patients followed for up to 5 years after trabeculectomy with 5-FU treatment are reported to have about a $50 \%$ failure rate compared with $74 \%$ in patients where 5 -FU was not used. ${ }^{13}$ Several studies indicate, however, that adverse effects may be associated with 5-FU, including the necessity for frequent injections, ocular epithelial toxicity, wound leaks and endophthalmitis. ${ }^{14-16}$ Trabeculectomy failure rates have also been reduced with the use of mitomycin $\mathrm{C}$, although serious complications associated with its use, including chronic repeated bleb leaks, scleral necrosis and avascular bleb formation, have also been observed in some cases. ${ }^{17-19}$ In vitro studies indicate that mitomycin $\mathrm{C}$ can be cytotoxic to vascular endothelial cells. ${ }^{20} \mathrm{~A}$ variety of other agents that may potentially modulate fibroblast function and proliferation continue to be investigated in vitro, ${ }^{2}$ including bleomycin, daunorubicin and mithramycin, ${ }^{21}$ interferon- $\alpha 2 b,{ }^{22}$ cytarabine, ${ }^{15}$ taxol and colchicine. $^{2}$

In the present study, bile acids and salts induced a time- and dose-dependent reduction in fibroblast viability. Both cell counts and MTT assays indicated that bile acids and salts (DA, NaD and $\mathrm{CA}$ ) inhibited growth of human Tenon's capsule fibroblasts compared with controls; fibroblast morphology was also affected by bile acids and salts, with an obvious reduction in cell density and extension of processes from fibroblast cell bodies. Both DA and $\mathrm{NaD}$ were more potent than CA (DA was slightly more potent than $\mathrm{NaD}$ ). Previous in vitro studies have similarly observed that DA and its conjugates are more toxic than other bile acids to a variety of cells including cultured human fibroblasts. ${ }^{7,8}$ The cytotoxicity of bile acids has been related to several factors including bile acid modulation of protein kinase $\mathrm{C}$ activity, ${ }^{23}$ enhancement of intracellular calcium levels ${ }^{24,25}$ and generation of free radicals associated with cell membrane damage and activation of phospholipase $C .{ }^{26}$ Cell membrane damage appears to be a function of bile acid detergency, where increased interaction between bile acids and cell membranes increases toxicity. ${ }^{27}$ More specifically, the increased potency of DA (and conjugates) may be due to increased detergency of these compounds compared with other bile acids such as CA; bile acid interactions with cellular membranes (and thus toxicity) appear to be lowered by the number and orientation of hydroxyl groups, and the formation of $\beta$-epimers. ${ }^{27}$

At the higher doses used, we observed fibroblast cytotoxicity, with marked morphological changes and significant reductions in viability. While bile acids and salts have been suggested to induce cytotoxicity via necrosis, ${ }^{8}$ recent in vitro studies indicate that bile salts can induce apoptotic involution of cells. ${ }^{8,9,28,29}$ For example, sodium deoxcycholate treatment of EBVtransformed lymphocytes can induce either apoptotic cell death or necrosis depending on concentration, ${ }^{9}$ and may also induce apoptotic involution of cultured colon goblet cells ${ }^{8}$ and colorectal tumour cells. ${ }^{29}$ The potential of bile acids and salts to induce apoptotic involution of human Tenon's capsule fibroblasts is currently being investigated.

Clinical observations in patients with obstructive jaundice and following bile duct surgery, have implicated bile acids and salts in regulating wound repair. ${ }^{5}$ Human bile, bile acid mixtures and individual bile salts, in particular deoxycholate salts, have also been reported to induce time- and dose-dependent cytotoxic effects in cultured human fibroblasts. ${ }^{6}$ Together with the present study, these observations suggest that bile acids and salts may be useful for inhibiting fibrosis associated with failure of trabeculectomy surgery. Further studies are required to investigate the cytotoxicity of bile acids and salts to other ocular cells, and the potential of bile acids and salts, particularly DA, to modulate fibroblast function.

\section{References}

1. Skuta, GL, Parrish AK. Wound healing in glaucoma filtering surgery. Surv Ophthalmol 1987;32:149-70.

2. Khaw PT, Occleston NL, Schultz G, Grierson I, Sherwood MB, Larkin G. Activation and suppression of fibroblast function. Eye 1994;8:188-95.

3. Gressel MG, Heuer DL, Parrish K. Trabeculectomy in young patients. Ophthalmology 1984;91:1242-6.

4. Beauchamp GR, Parks MM. Filtering surgery in children: barriers to success. Ophthalmology 1979;86:170-80.

5. Waltman W. Physiologic studies in cases of strictures of the common bile duct. Ann Surg 1953;138:609-18.

6. Trias X, Strebel HM, Paumgartner G, Wiesmann UN. Effects of bile and bile acids on human fibroblasts. Eur J Clin Invest 1977;7:189-94.

7. Zimber A, Chedeville A, Gespach C, Abita J-P. Inhibition of proliferation and induction of monocytic differentiation in HL60 human promyelocytic leukemia cells treated with bile acids in vitro. Int J Cancer 1994;59:71-7.

8. Payne CM, Bernstein H, Garewal H. Role of apoptosis in biology and pathology: resistance to apoptosis in colon carcinogenesis. Ultrastructural Pathol 1995;19:221-48.

9. Samaha HS, Asher E, Payne CM. Evaluation of cell death in EBV-transformed lymphocytes using agarose gel electrophoresis, light microscopy and electron microscopy Induction of classic apoptosis by the bile salt, sodium deoxycholate. Leukemia Lymphoma 1995;19:95-105.

10. Saettone MF, Chetoni P, Cerbai R, Mazzanti G, Braghiroli L. Evaluation of ocular permeation enhancers: in vitro effects on corneal transport of four beta-blockers and in vitro/in vivo toxic activity. Int J Pharmaceutics 1996;142:103-13. 
11. Stiehl A, Rudolph G, Raedsch R, Moller B, Hopf U, Lotterer $E$, et al. Ursodeoxycholic acid-induced changes of plasma and urinary bile acids in patients with primary biliary cirrhosis. Hepatology 1990;12:492-7.

12. Diaferia A, Nicastri PL, Tartagni M, Loizzi P, Iacovizzi C, Di Leo A. Ursodeoxycholic acid therapy in pregnant women with choleostasis. Int J Gynecol Obstet 1996;52:133-40.

13. Five year follow-up of the fluorouracil filtering surgery study. The Fluorouracil Filtering Surgery Study Group. Am J Ophthalmol 1996;121:349-66.

14. Lee AD, Hersch P, Kersten D, Melamed S. Complications of subconjunctival 5-fluorouracil following glaucoma filtering surgery. Ophthalmic Surv 1987;18:197-200.

15. Lee DA, Tehrani SS, Kitada S. The effect of 5-fluorouracil and cytarabine on human fibroblasts from Tenon's capsule. Invest Ophthalmol Vis Sci 1990;31:1848-55.

16. Frank WA, Hitchings RA. Complications of 5-fluorouracil after trabeculectomy. Eye 1991;5:385-9.

17. Prata JA, Seah SKL, Minckler DS, Baerveldt G, Lee PP. Postoperative complications and short-term outcome after 5-fluorouracil or mitomycin C trabeculectomy. J Glaucoma 1995;4:25-31.

18. Costa VP, Moster MR, Wilson RP, Schmidt CM. Effects of topical mitomycin $C$ on primary trabeculectomies and combined procedures. Br J Ophthalmol 1993;77:693-7.

19. Singh J, O'Brien C, Chawala HB. Success rate and complications of intraoperative $0.2 \mathrm{mg} / \mathrm{ml}$ mitomycin $\mathrm{C}$ in trabeculectomy surgery. Eye 1995;9:460-6.

20. Smith S, D'Amore PA, Dreyer EB. Comparative toxicity of mitomycin $\mathrm{C}$ and 5-fluorouracil in vitro. Am J Ophthalmol 1994;118:332-7.
21. Lee DA, Lee TC, Cortes AE, Kitada S. Effects of mithramycin, mitomycin, daunorubicin, and bleomycin on human subconjunctival fibroblast attachment and proliferation. Invest Ophthalmol Vis Sci 1990;31:2136-44.

22. Gillies M, Su T, Sarossy M, Hollows F. Interferon- $\alpha 2 b$ inhibits proliferation of human Tenon's capsule fibroblasts. Graefes Arch Clin Exp Ophthalmol 1993;231:118-21.

23. Fitzer CJ, O'Brian CA, Guillem JG, Weinstein IB. The regulation of protein kinase $C$ by chenodeoxycholate, deoxycholate and several structurally related bile acids. Carcinogenesis 1987;8:217-20.

24. Anwer MS, Engelking LR, Nolan K, Sullivan D, Zimniak P, Lester R. Hepatotoxic bile acids increase cytosolic $\mathrm{Ca}^{2+}$ activity of isolated rat hepatocytes. Hepatology 1988;8:887-91.

25. Combettes L, Dumont M, Berthon B, Erlinger S, Claret M. Release of calcium from the endoplasmic reticulum by bile acids in rat liver cells. J Biol Chem 1988;263:2299-303.

26. Nomoto K, Morotomi M, Miyake M, Xu D-B, LoGerfo PP, Weinstein IB. The effects of bile acids on phospholipase $C$ activity in extracts of normal human colon mucosa and primary colon tumours. Mol Carcinog 1994;9:87-94.

27. Garner CM, Mills CO, Elias E, Neuberger JM. The effect of bile salts on human vascular endothelial cells. Biochim Biophys Acta 1991;1091:41-5.

28. Patel T, Gores GJ. Inhibition of bile-salt-induced hepatocyte apoptosis by the antioxidant lazaroid U83836E. Toxicol Appl Pharmacol 1997;142:116-22.

29. Hague A, Elder DJE, Hicks DJ, Paraskeva C. Apoptosis in colorectal tumour cells: induction by the short chain fatty acids butyrate, propionate and acetate and by the bile salt deoxycholate. Int J Cancer 1995;60:400-6. 